\title{
The Role of Ice Particle Shapes and Size Distributions in the Single Scattering Properties of Cirrus Clouds
}

\author{
ANDREAS MACKE \\ Department of Applied Physics, Columbia University, New York, New York \\ Peter N. FRANCIS \\ Meteorological Research Flight, Meteorological Office, Farnborough, United Kingdom \\ GREG M. MCFARQuHAR \\ National Center for Atmospheric Research, Boulder, Colorado \\ STEFAN KINNE \\ Bay Area Environmental Research Institute/NASA Ames, Moffet Field, California
}

(Manuscript received 1 November 1996, in final form 20 January 1998)

\section{ABSTRACT}

\begin{abstract}
The roles of ice particle size distributions (SDs) and particle shapes in cirrus cloud solar radiative transfer are investigated by analyzing SDs obtained from optical array probe measurements (particle sizes larger than 20-40 $\mu \mathrm{m}$ ) during intensive field observations of the International Cirrus Experiment, the European Cloud and Radiation Experiment, the First ISCCP Regional Experiment, and the Central Equatorial Pacific Experiment. It is found that the cloud volume extinction coefficient is more strongly correlated with the total number density than with the effective particle size. Distribution-averaged mean single scattering properties are calculated for hexagonal columns, hexagonal plates, and polycrystals at a nonabsorbing $(0.5 \mu \mathrm{m})$, moderately absorbing $(1.6$ $\mu \mathrm{m})$, and strongly absorbing $(3.0 \mu \mathrm{m})$ wavelength. At $0.5 \mu \mathrm{m}(1.6 \mu \mathrm{m})(3.0 \mu \mathrm{m})$, the spread in the resulting mean asymmetry parameters due to different SDs is smaller than (comparable to) (smaller than) the difference caused by applying different particle shapes to these distributions. From a broadband solar radiative transfer point of view it appears more important to use the correct particle shapes than to average over the correct size distributions.
\end{abstract}

\section{Introduction}

The solar radiative properties of cirrus clouds are determined by the shape and number density distributions of ice particles as well as by the spatial structure of the clouds themselves. In recent years, most work has been focused on the shape problem, that is, on the nonsphericity of atmospheric ice crystals. Based on the ray optics approximation, single scattering properties have been calculated for regular hexagonal cylinders (e.g., Takano and Jayaweera 1985), for bullets, bullet rosettes, various stellar and dendritic crystals (Macke 1993; Iaquinta et al. 1995; Takano and Liou 1995; Macke et al. 1996), and for highly complex shaped polycrystals (Macke et al. 1996). The problem of light scattering by

Corresponding author address: Dr. Andreas Macke, Institut für Meereskunde, Universität zu Kiel, Düsternbrooker Weg 20, D-24105 Kiel, Germany.

E-mail: amacke@ifm.uni-kiel.de small ice crystals, where the ray optics approximation may not be valid, has also been investigated (Yang and Liou 1995; Macke et al. 1996).

Comparisons of modeled and observed broadband fluxes during the First ISCCP (International Satellite Cloud Climatology Project) Regional Experiment (FIRE) (Starr 1987) have shown that light scattering by real ice crystals is more isotropic than from hexagonal particles. (Kinne et al. 1992; Stackhouse and Stephens 1991). Direct and indirect measurements of ice particle phase functions in cirrus clouds (Gayet et al. 1995; Francis 1995; Posse and von Hoyningen-Huene 1996; Spinhirne et al. 1996) confirm this finding. At present, it seems likely that particles exhibiting a greater degree of irregularity or randomness than hexagonal columns need to be taken into account to explain these results.

The single scattering results have to be averaged over certain ice crystal size distributions (SDs) before they can be used in radiative transfer calculations. Kinne and Liou (1989) calculated solar broadband planetary al- 
bedos for five different distributions assuming hexagonal cylinders and surface equivalent spheres. These distributions have been regarded as characteristic for cirrostratus, cirrus uncinus, warm cirrus, cold cirrus, and tropical cirrus. This paper has already demonstrated that different assumptions for both particle sizes and shapes lead to significant changes in the solar energy transport.

The strong spatial variability of ice particle shapes and number concentrations as measured during the intensive field campaigns of the European Cloud Radiation Experiment (EUCREX) (Raschke and Coauthors 1996) and FIRE makes it difficult to associate a single characteristic particle shape or size distribution to a certain cirrus cloud type.

In this paper, the implications of certain choices regarding ice particle shapes and sizes on the "SD averaged" single scattering properties are discussed. The following three particle shapes are considered here: solid hexagonal columns, solid hexagonal plates, and polycrystals. The scattering properties of these particle types are briefly discussed in section 2 . Section 3 provides an analysis of a large number of in situ measured ice particle size distributions that have been obtained during the International Cirrus Experiment (ICE) (Raschke et al. 1990), EUCREX, FIRE, and the Central Equatorial Pacific Experiment (CEPEX). The influence of particle shapes and size distributions on the mean single scattering properties of ice crystals are compared in section 4 .

It should be noted that our approach could be regarded as being not entirely self-consistent, in that in situ measurements of ice crystals usually contain information about the sizes and shapes of the particles, whereas we have only considered the size information in the present study. We have used the size/shape measurements to obtain the frequency distributions of particles with areaequivalent circular radii, and then applied this information to the three particle shape assumptions mentioned above, that is, columns, plates, and polycrystals. The main reason for this simplification is that the measured shape information is often not sufficient to reconstruct the actual three-dimensional geometry of an ice crystal. Furthermore, the reduction to three essentially different particle shapes is more likely to match the capability of shape predictions in cloud dynamical models.

\section{Ice particle shapes and scattering properties}

The shapes of atmospheric ice crystals range from relatively regular hexagonal cylinders to aggregates of those to highly complex polycrystals. According to Macke et al. (1996), light scattering by solid hexagonal columns appears representative of the scattering properties of most columnlike particles such as hollow columns and solid or hollow bullets. Scattering by aggregates of columnlike particles (bullet rosettes) may also be substituted by that of their single components (Macke 1993; Iaquinta et al. 1995). The dependence of light
TABle 1. Power-law coefficients $A$ and $B$ for length diameter relationships (in $\mathrm{cm}$ ) for hexagonal crystals reported by Auer and Veal (1970) and Mitchell and Arnott (1994). Here $d=A l^{B}$ for columnlike crystals, whereas $l=A d^{B}$ for platelike crystals.

\begin{tabular}{lllc}
\hline \hline \multicolumn{1}{c}{ Crystal type } & \multicolumn{1}{c}{ A } & \multicolumn{1}{c}{$\begin{array}{c}\text { Maximum } \\
\text { dimension } \\
\text { range }(\mu \mathrm{m})\end{array}$} \\
\hline Hexagonal plate & 2.02 & 0.449 & $20-3000$ \\
Small hexagonal columns & 0.7 & 1.0 & $20-100$ \\
Large hexagonal columns & 6.96 & 0.5 & $100-3000$ \\
\hline
\end{tabular}

scattering on crystal type is much stronger for platelike particles. However, for reasons of simplicity, only solid hexagonal plates are considered in this study. Scattering by complex shaped polycrystals is approximated by a randomized Koch fractal as introduced in Macke et al. (1996). A number of comparisons between observed and modeled radiance fields within and above cirrus clouds (Chepfer et al. 1997; Hignett et al. 1997; Descloitres et al. 1997) have shown that applying this particle type to the model calculations often produces much better agreement than using hexagonal symmetric crystals.

Empirical relationships between length $l$ and diameter $d$ for columnlike crystals and thickness $l$ and diameter $d$ for platelike crystals, both reported by Auer and Veal (1970), have been adopted in the present study. They are given in power-law form as

$$
l=A d^{B} \text { for plates, } \quad d=A l^{B} \text { for columns. }
$$

The empirical constants $A$ and $B$ as well as the measured range of maximum dimensions are listed in Table 1 . The term "maximum dimension" refers to the length of the column and the diameter of the plate. The power-law parameterizations for small and large columns were later introduced by Mitchell and Arnott (1994) after reanalyzing the corresponding measurement results of Auer and Veal (1970).

Figure 1 shows scattering phase functions at a wavelength of $0.5 \mu \mathrm{m}$ for the randomly oriented crystals: hexagonal column, a hexagonal plate, and a polycrystal. Only the ray tracing part is shown in this diagram (no diffraction) to emphasize the dependence of the phase function on particle shape. While the hexagonal particle shows a number of scattering features like pronounced forward and backscattering peaks as well as halos, the phase function of the polycrystal is essentially featureless.

In order to perform SD averages, the single scattering properties for columns, plates, and polycrystals have been calculated for the six sizes 25, 50, 100, 200, 400, and $800 \mu \mathrm{m}$. For columns and plates, these sizes refer to the maximum dimension. For the polycrystal, these sizes denote the length of the initial tetrahedron (Macke et al. 1996). The latter is about $15 \%$ smaller than the particles maximum dimension.

The three wavelengths of $\lambda=0.5,1.6$, and $3.0 \mu \mathrm{m}$ were selected to represent nonabsorbing, moderately ab- 


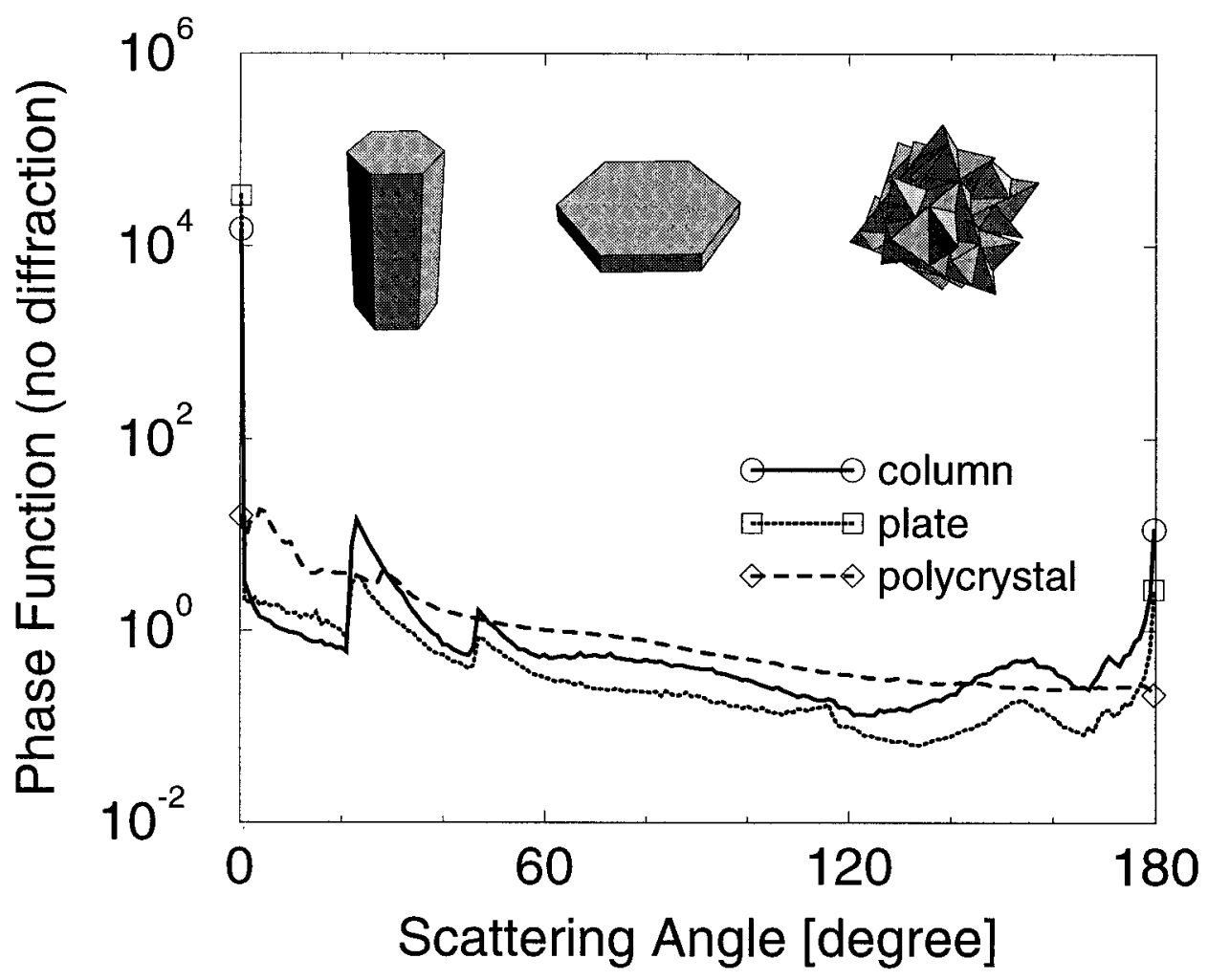

FIG. 1. Ray tracing scattering phase function (excluding diffraction) for randomly oriented columns, plates, and polycrystals with a maximum dimension of $200 \mu \mathrm{m}$ at a wavelength of $0.5 \mu \mathrm{m}$. Aspect ratio $(l / d)$ for the column and the plate is 2.0 and 0.1 , respectively.

sorbing, and strongly absorbing solar spectral regions, respectively. The optical constants of ice at these wavelengths are taken from Warren (1984). Tables 2-4 show the asymmetry parameter $g$ (including diffraction) and single scattering albedos $\omega_{0}$ for all particle shapes and particle sizes at the three wavelengths. A detailed discussion of the dependence of light scattering by ice crystals on shape, size, and wavelength can be found in Takano and Liou (1989, 1995), Macke et al. (1996), and Macke and Mishchenko (1996).

Note that using a size-independent particle geometry like the (fractal) polycrystal may be problematic for calculating SD averages of single scattering properties for irregular ice crystals. The analysis of replicator data

TABLE 2. Asymmetry parameter and single scattering albedo (in parentheses) for hexagonal columns, hexagonal plates, and polycrystals for six size classes at a wavelength of $0.5 \mu \mathrm{m}$.

\begin{tabular}{cccc}
\hline \hline $\begin{array}{c}\text { Maximum } \\
\text { dimension } \\
(\mu \mathrm{m})\end{array}$ & Columns & Plates & Polycrystals \\
\hline 25 & $0.7875(1.0000)$ & $0.8320(1.0000)$ & $0.7390(1.0000)$ \\
50 & $0.7889(1.0000)$ & $0.8619(1.0000)$ & $0.7402(1.0000)$ \\
100 & $0.7877(1.0000)$ & $0.8890(1.0000)$ & $0.7392(1.0000)$ \\
200 & $0.8153(1.0000)$ & $0.9101(1.0000)$ & $0.7396(1.0000)$ \\
400 & $0.8386(1.0000)$ & $0.9283(1.0000)$ & $0.7405(1.0000)$ \\
800 & $0.8532(1.0000)$ & $0.9432(1.0000)$ & $0.7394(1.0000)$ \\
\hline
\end{tabular}

(maximum dimension $<200 \mu \mathrm{m}$ ) and optical array probe measurements indicate that larger irregular crystals are less compact (i.e., less dense) than smaller ones (e.g., Mitchell and Arnott 1994). The (fractal) polycrystal shows mass-dimension relationships that are very close to those obtained from the replicator measurements for irregular ice crystals smaller than $100 \mu \mathrm{m}$ (see Table 3 in Mitchell et al. 1996). Therefore, applying the polycrystal model to large ice crystals may lead to an overestimation of ice particle mass and thus to erroneously low values for the single scattering albedo, at least for the moderately absorbing wavelength. It should be noted, however, that reliable measurements of aspect ratio and mass for irregular crystals are not generally available at the present time. Strictly speaking,

TABle 3. Same as Table 2 but at a wavelength of $1.6 \mu \mathrm{m}$.

\begin{tabular}{cccc}
\hline \hline $\begin{array}{c}\text { Maximum } \\
\text { dimension } \\
(\mu \mathrm{m})\end{array}$ & Columns & Plates & Polycrystals \\
\hline 25 & $0.8149(0.9739)$ & $0.8499(0.9782)$ & $0.7417(0.9790)$ \\
50 & $0.8244(0.9499)$ & $0.8829(0.9657)$ & $0.7635(0.9590)$ \\
100 & $0.8392(0.9066)$ & $0.9107(0.9486)$ & $0.7840(0.9224)$ \\
200 & $0.8730(0.8667)$ & $0.9337(0.9287)$ & $0.8127(0.8595)$ \\
400 & $0.9035(0.8211)$ & $0.9520(0.9085)$ & $0.8554(0.7659)$ \\
800 & $0.9246(0.7733)$ & $0.9635(0.8927)$ & $0.9134(0.6547)$ \\
\hline
\end{tabular}


TABLE 4. Same as Table 2 but at a wavelength of $3.0 \mu \mathrm{m}$

\begin{tabular}{cccc}
\hline \hline $\begin{array}{c}\text { Maximum } \\
\text { dimension } \\
(\mu \mathrm{m})\end{array}$ & Columns & Plates & Polycrystals \\
\hline 25 & $0.9008(0.6157)$ & $0.9030(0.6196)$ & $0.8576(0.6020)$ \\
50 & $0.9003(0.6144)$ & $0.9043(0.6210)$ & $0.8553(0.5912)$ \\
100 & $0.9000(0.6139)$ & $0.9058(0.6238)$ & $0.8758(0.5855)$ \\
200 & $0.9014(0.6162)$ & $0.9085(0.6277)$ & $0.8803(0.5825)$ \\
400 & $0.9035(0.6193)$ & $0.9104(0.6313)$ & $0.8800(0.5814)$ \\
800 & $0.9061(0.6236)$ & $0.9118(0.6341)$ & $0.8777(0.5808)$ \\
\hline
\end{tabular}

the above argument could also be applied to the other two particle shapes, since differences clearly exist between real ice columns or plates and the pristine hexagonal particles used for the calculations in this study. Using idealized particle shapes will never satisfy real situations in cirrus clouds. On the other hand, taking totally realistic ice crystal geometries into account is far beyond the present observational and theoretical capabilities.

\section{Ice particle size distributions}

A large number of flights during various field campaigns have provided a huge amount of in situ measurements of ice particle SDs (e.g., Gayet et al. 1996; Heymsfield and Miloshevich 1995; McFarquhar and Heymsfield 1996). The strong scatter in the reported SDs is mainly due the fact that the measurements were taken in very different cloud conditions and that cirrus clouds have a large degree of natural variability. Furthermore, some of the scatter may result from problems associated with data aquisition software, the electronics, and calibration (Gayet et al. 1993).

This spread in the in situ ice particle measurements motivates a statistical approach for determining the influence of SDs on the particles' scattering properties. Rather than choosing one mean SD for a certain cloud type as has been done in previous studies (Kinne and Liou 1989; Takano and Liou 1989), many SDs were taken into account to obtain averaged single scattering properties for each distribution. This approach renders it possible to obtain not only the mean value but also higher order statistical moments of the SD-weighted scattering properties.

The SD data have been collected from measurements during ICE, FIRE, EUCREX, and CEPEX. Particle sizes were measured with a two-dimensional cloud probe (2DC), a two-dimensional precipitation probe (2DP), and a forward scattering spectrometer probe (FSSP). While the 2D probes essentially measure the cross-sectional area $A$ of ice particles, the FSSP is an indirect sizing probe that converts measured intensities to a sphere radius assuming spherical particle shapes. Its response to nonspherical crystals is not known at the present (Gardiner and Hallet 1985). Furthermore, the FSSP may also have problems with interference of small crys-
TABLE 5. Size range and resolution (in $\mu \mathrm{m}$ ) of the 2DC and 2DP probes operated during ICE/EUCREX, FIRE, and CEPEX.

\begin{tabular}{llc}
\hline \hline Experiment & \multicolumn{1}{c}{ 2DC } & 2DP \\
\hline ICE/EUCREX & $25-800,25$ & $200-6400,200$ \\
FIRE & $25-1700,25$ & $100-4000,100$ \\
CEPEX & $40-1000,30$ & $120-6000,120$ \\
\hline
\end{tabular}

tal measurement due to presence of larger ice crystals. Therefore, FSSP data are not considered in this paper. Nominal size ranges and resolutions of the 2DC and 2DP probes are shown in Table 5, where "size" is defined as the maximum particle dimension either parallel or normal to the aircraft flight direction. According to Baumgardner and Korolev (1997) and Hobbs et al. (1996) particles smaller than about $100 \mu \mathrm{m}$ may be underestimated by the optical array probes (OAP) due to electronic response time limitations at high air speeds. Thus, the lower size ranges given in Table 5 may be too small.

In this paper the size of the particles is defined by the radius $r_{\text {eqv }}$ of a cross-sectional equivalent sphere. Here $N(r)$ denotes a SD given in number of particles per volume. Therefore, the total number of particles per unit volume is given by

$$
N_{\mathrm{total}}=\sum_{i} N_{i}\left(r_{\mathrm{eqv}, i}\right), \quad r_{\mathrm{eqv}, i}=\sqrt{A_{i} / \pi},
$$

where $i$ denotes a size interval. The volume extinction coefficient $\beta_{\text {ext }}$ for a homogeneous cloud parcel is given by

$$
\beta_{\mathrm{ext}}=Q_{\mathrm{ext}} \sum_{i} N_{i}\left(r_{\mathrm{eqv}, i}\right) A_{i},
$$

where $Q_{\text {ext }}=2$ is the extinction efficiency for large ice crystals at solar wavelengths.

The effective radius $r_{\text {eff }}$ of a given SD $N(r)$ may be defined by the ratio of the third to the second moment of the distribution;

$$
r_{\mathrm{eff}}=\frac{\sum_{i} N_{i}\left(r_{\mathrm{eqv}, i}\right) r_{\mathrm{eqv}, i}^{3}}{\sum_{i} N_{i}\left(r_{\mathrm{eqv}, i}\right) r_{\mathrm{eqv}, i}^{2}} .
$$

Note that the above equation is only one way of many possible ways of defining effective radius for a population of ice crystals. See McFarquhar and Heymsfield (1998) for a discussion of this problem.

Each SD used in this study results from averaging the data along a horizontal flight leg. The corresponding measurement distance is about $100-150 \mathrm{~km}$, depending on the speed of the aircraft and the choice of the flight pattern.

Examples of SDs for a midlatitude cirrus as measured during EUCREX and a tropical cirrus as measured during CEPEX are shown in Figs. 2 and 3. The EUCREX results are from a combined $2 \mathrm{DC}$ and 2DP measurement whereas the CEPEX data are based on 2DC measurements only.

Note that the $2 \mathrm{D}$ probe SDs do not show a local 


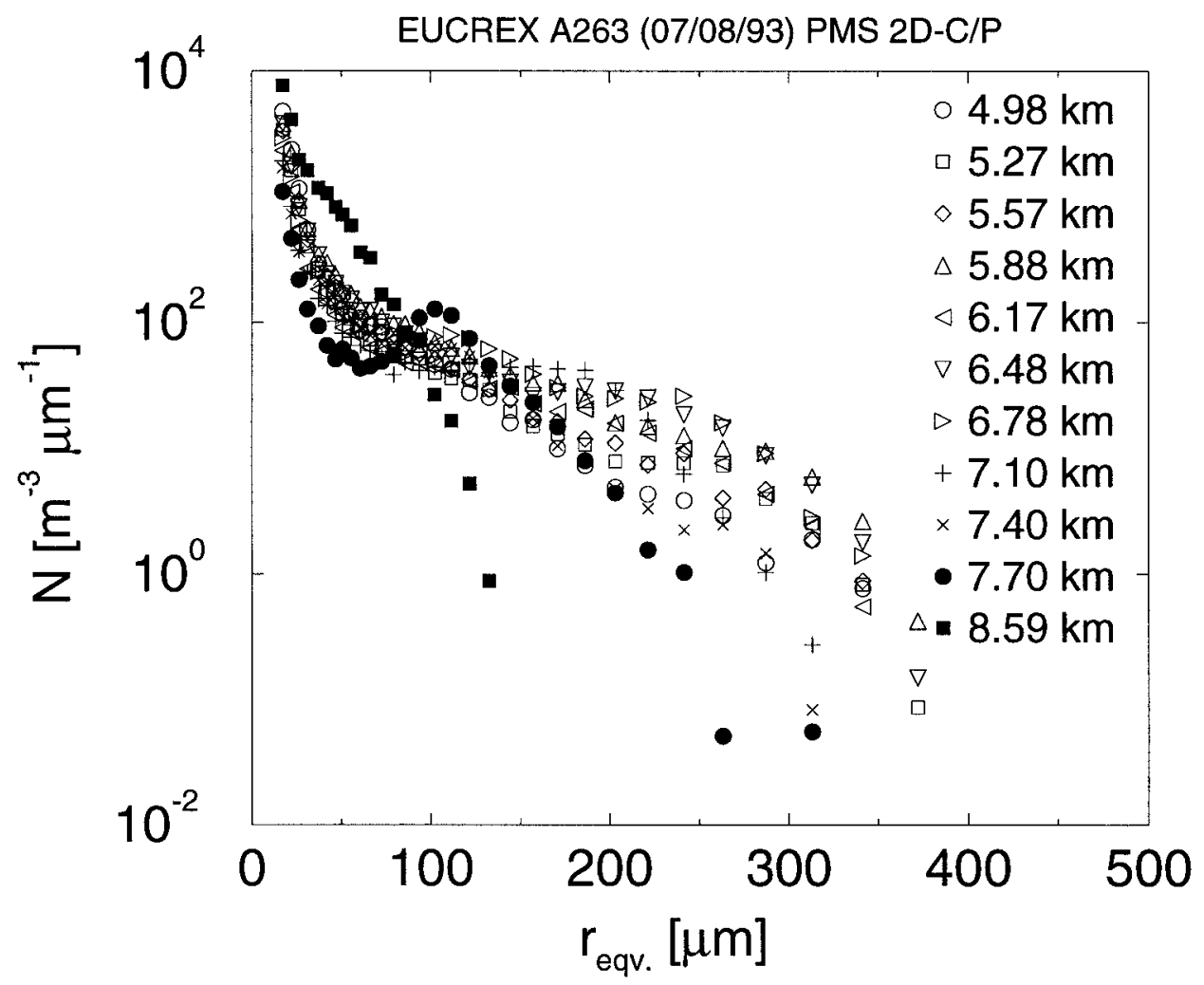

FIG. 2. Particle SDs obtained during a EUCREX flight mission on 8 July 1993. Each spectrum resulted from averaging along a horizontal flight leg.

maximum in number concentration. Based on video image measurements (Heymsfield and McFarquhar 1996; McFarquhar and Heymsfield 1997; Kinne and Coauthors 1997) and balloonborne replicator measurements, this maximum occurs at a size of about $10 \mu \mathrm{m}$. The contribution of those small particles not detected by the 2DC measurements to the overall extinction appears to be small, at least for the radiatively important cases of moderate to large total volume extinction (Heymsfield and McFarquhar 1996; Kinne and Coauthors 1997). However, one has to bear in mind that all conclusions that are based on analyzing OAP data only may be subject to changes when small ice particles turn out to play a bigger role than anticipated in the present paper. From the point of view of single scattering theory, small ice particles may violate the applicability of the ray optics approximation. However, it has been shown that the combination of ray optics with exact theories like the T-matrix method (Macke et al. 1995) or the finite difference time domain method (Yang and Liou 1995) essentially covers the entire size spectra of atmospheric ice particles. Therefore, a consideration of small ice particles in single scattering calculations is basically hindered by the lack of information regarding size, shape, and number concentration of these small particles.

The size parameter $x=2 \pi r / \lambda$ for the smallest par- ticles considered in our study is about 200 at visible wavelengths $(0.5 \mu \mathrm{m})$ and about 30 at the low-frequency end of the solar spectrum $(4 \mu \mathrm{m})$. Given the spectral curve of the incoming solar intensity, geometric optics appears to be a reliable approximation for most of the solar input. However, one has to bear in mind that this situation is problematic in the solar infrared, particularly for the smallest crystals. On the other hand, both the nonsphericity of ice crystals and the fact that ice is absorbing in the solar IR reduces the errors in the ray optics approximation (Macke et al. 1995; Macke et al. 1997; Wielaard et al. 1997).

Equations (2)-(4) show that the total number concentration and effective radius are important in determining the volume extinction coefficient. The crucial difference between these two parameters is that $r_{\text {eff }}$ determines both the mean single scattering properties (i.e., the single scattering albedo and the asymmetry parameter) and the extinction coefficient, whereas $N_{\text {total }}$ affects the extinction coefficient only.

Figure 4 shows the dependence of the volume extinction coefficient on size and number density respectively for all SDs used in this study. Interestingly, the extinction and thus the optical thickness is more strongly correlated with particle number concentration than with the particle size. As expected, extinction increases with particle size. However, the overall scatter is stronger 


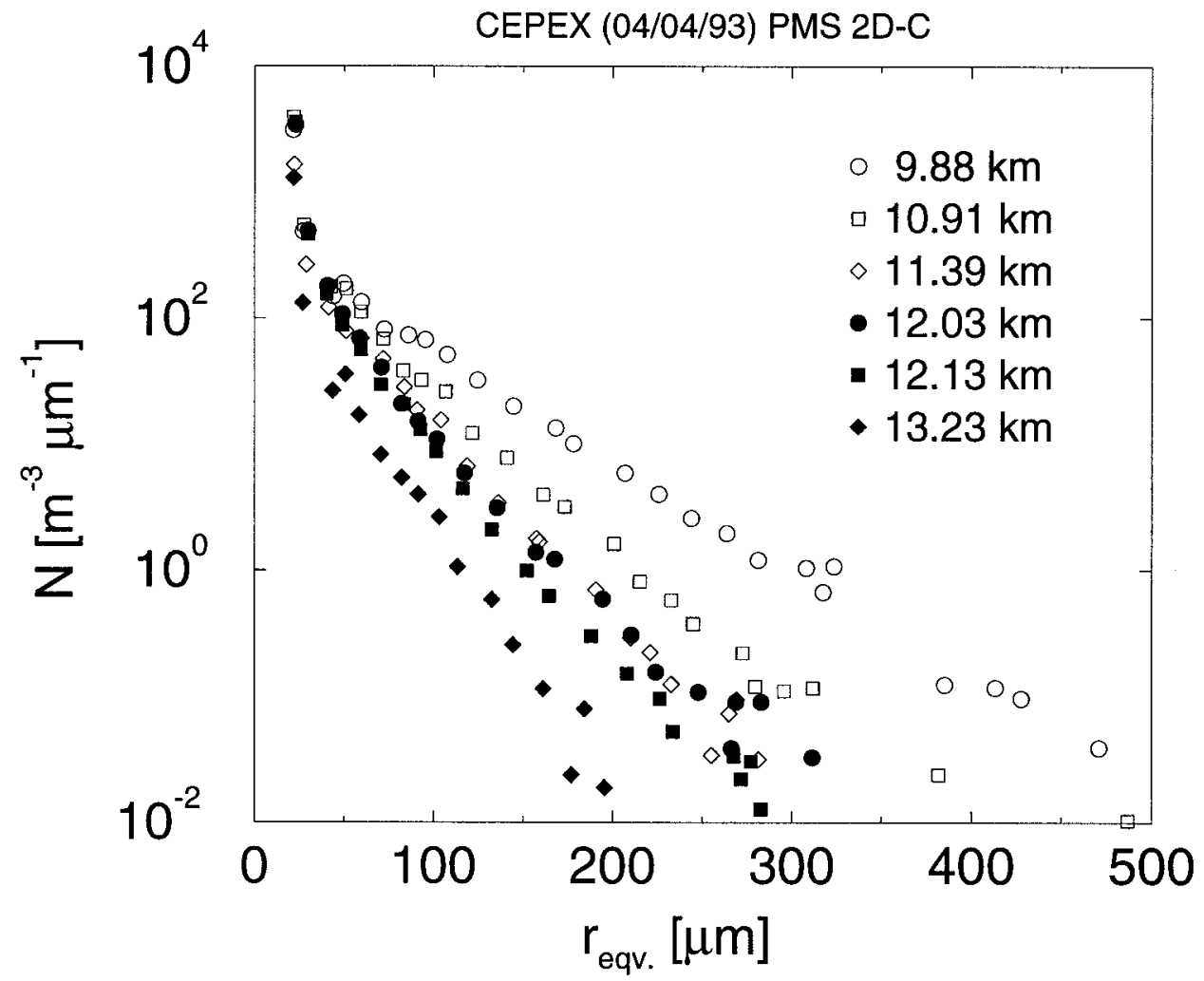

FIG. 3. Same as Fig. 5 but for a CEPEX flight mission on 4 April 1993.

than the magnitude of this slope. Note that the SDs from the three midlatitude experiments cover essentially the same data space whereas the CEPEX data show a tendency toward higher extinction coefficients. This is to a small degree caused by larger particle sizes and to a larger degree due to the higher number densities. The bottom diagram in Fig. 4 shows that effective particle size and total number concentration are essentially uncorrelated. Applying power-law fits to the data shown in Fig. 4 yields for the $r_{\text {eff }}-\beta_{\text {ext }}$, the $N_{\text {total }}-\beta_{\text {ext }}$, and the $N_{\text {total }}-r_{\text {eff }}$ data pairs correlation coefficients of $0.408,0.777$, and -0.155 , respectively.

Table 6 shows the mean value and standard deviation (in brackets) of effective radii $r_{\text {eff }}$, total number density $N_{\text {total }}$, and volume extinction coefficient $\beta_{\text {ext }}$ for all SDs separated into midlatitude and tropical cirrus. These numbers again show that the larger extinction for the tropical cirrus SDs results basically from the larger number density than from the larger particle sizes. However, this conclusion has to be regarded as preliminary since particles with equal-sphere-area equivalent radii smaller than about $20-40 \mu \mathrm{m}$ are not considered here. In theory, a large number of undetected small ice crystals for either the midlatitude or tropical cirrus cases may reduce or enhance these differences. However, the current set of analyzed measurements of small ice crystals is too small to assess this problem.

Note that the scatter as shown in the three diagrams does not necessarily reflect a random or chaotic nature of cirrus clouds. A correlation of the parameter discussed above (i.e., $N_{\text {total }}, r_{\text {eff }}$, and $\beta_{\text {ext }}$ ) with temperature, humidity, vertical velocity, and other (thermo-)dynamical properties may give much stronger correlations (e.g., Heymsfield and Miloshevich 1995). Furthermore, there might be more hope for better correlations for those clouds that are more associated with large-scale lifting than those associated with deep convection. However, there will always remain a certain degree of natural variability that will defy a perfect correlation between the microphysical properties and their causes.

\section{Single scattering properties}

The mean scattering phase matrix $\left\langle P_{i, j}(\theta)\right\rangle(i, j=1$, $\ldots, 4)$ and mean single scattering albedo $\left\langle\omega_{0}\right\rangle$ for a certain size distribution $N(r)$ and a certain particle shape are given by

$$
\langle X\rangle=\frac{\sum_{r} X(r) N(r) C(r)}{\sum_{r} N(r) C(r)}, \quad X=P(\theta), \omega_{0},
$$

where $C(r)$ denotes the scattering cross section at size $r$. At nonabsorbing wavelengths $C(r)$ equals twice the projected area $A(r)$. The analysis of the scattering phase matrix is limited to the asymmetry parameter in this work, 

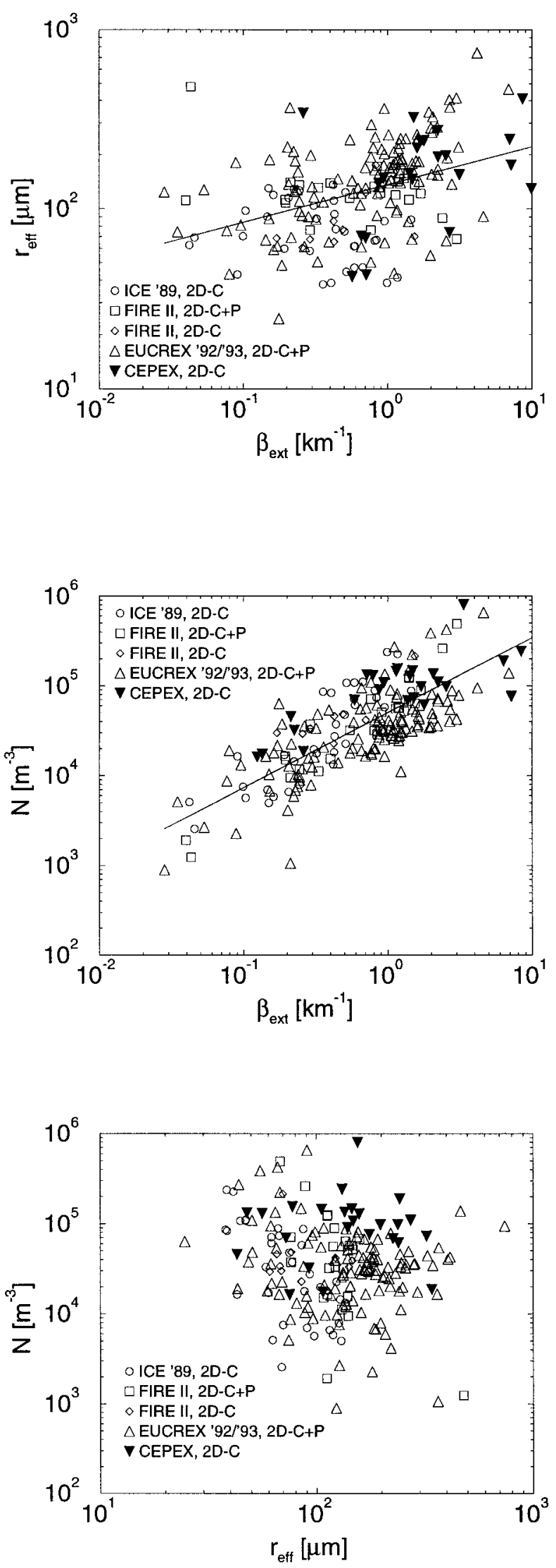

TABLE 6. Mean value and standard deviation (in parentheses) of effective radii $r_{\text {eff }}$, total number density $N_{\text {total }}$, and volume extinction coefficient $B_{\text {ext }}$ for all 2D SDs separated by midlatitude and tropical cirrus.

\begin{tabular}{lcc}
\hline \hline & Midlatitudes & Tropics \\
& $(185$ samples $)$ & $(26$ samples $)$ \\
\hline$r_{\text {eff }}(\mu \mathrm{m})$ & $144(93)$ & $168(94)$ \\
$N_{\text {total }}\left(l^{-1}\right)$ & $55(80)$ & $165(236)$ \\
$\beta_{\text {ext }}\left(\mathrm{km}^{-1}\right)$ & $0.92(0.90)$ & $2.20(2.46)$ \\
\hline
\end{tabular}

$$
\langle g\rangle=\int_{\Omega}\left\langle P_{1,1}(\theta)\right\rangle \cos \theta d \Omega,
$$

where $\theta$ denotes the scattering angle and $\Omega$ refers to a solid angle interval. Though important for (polarized) remote sensing, a discussion of the angular dependence of scattered (polarized) intensity would be beyond the scope of this paper. Furthermore, $\langle g\rangle$ and $\omega_{0}$ are the most important single scattering parameters for determining the amount of reflected and absorbed energy (e.g., Stackhouse and Stephens 1991).

Figures 5 and 6 show the frequency distributions of $\langle g\rangle$ at $0.5,1.6$, and $3.0 \mu \mathrm{m}$, and the distribution of $\left\langle\omega_{0}\right\rangle$ at 1.6 and $3.0 \mu \mathrm{m}$ for the 185 midlatitude SDs. The corrresponding mean values and standard deviations are listed in Table 7. The 26 SDs from CEPEX are not sufficient to provide similar statistics for the tropical cirrus data.

Dealing with $0.5 \mu \mathrm{m}$ first, we see that the asymmetry parameter varies significantly for distributions of columns and plates. This variation is basically due to the size dependence of the particles aspect ratios as discussed in section 2. Since the same shape for polycrystals is used at all sizes, the asymmetry parameter of this particle type shows only small variations. Note that the magnitude of the asymmetry parameter is much more sensitive to the choice of particle shape than to the size distributions. In spite of the strong scatter in the SDs as shown in Fig. 4, none of the asymmetry parameters overlap at $0.5 \mu \mathrm{m}$ for the different particle types. For example, the differences between $\langle g\rangle$ for columns and plates are about 6 times larger than the standard deviations for the individual distributions.

Turning to $1.6 \mu \mathrm{m}$, the additional size dependence at this wavelength due to absorption leads to a larger spread in $g$ (compared to the situation at $0.5 \mu \mathrm{m}$ ) and moves the $g$ frequency distribution to larger values. Figure 6 and Table 7 show that the larger spread in $g$ for columns and polycrystal at $1.6 \mu \mathrm{m}$ is essentially caused by the large scatter in the single scattering albedo of

$\leftarrow$

FIG. 4. Volume extinction coefficient vs effective particle radius (top diagram) and vs total number concentration (middle diagram), as well as effective radius vs number concentration (bottom diagram) for all SDs used in this study. The solid lines show power-law fits. 

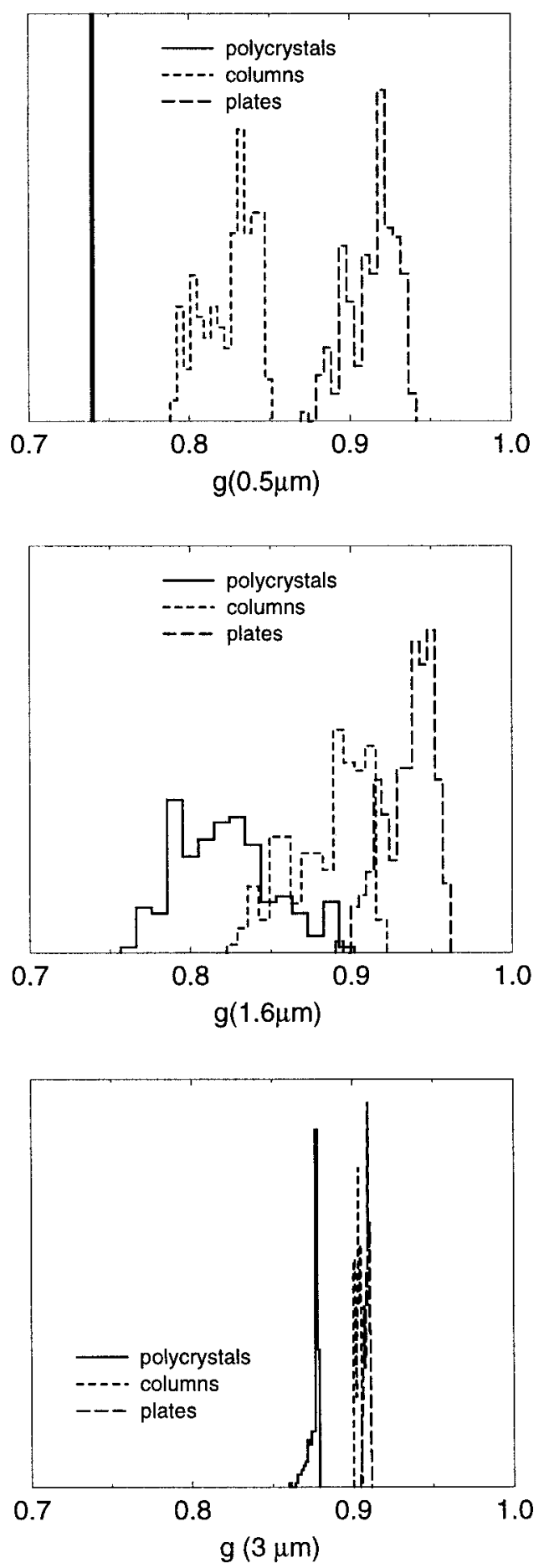

FIG. 5. Frequency distributions (arbitrary units) of asymmetry parameter at $0.5,1.6$, and $3.0 \mu \mathrm{m}$ for the midlatitude SDs.

these crystal types. Columns and polycrystals provide similar values for $\left\langle\omega_{0}\right\rangle$, that is, in mean absorption strength. However, the scatter is smaller for columns. For most SDs scattering by plates is still more anisotropic than by columns and polycrystals. Although ab-
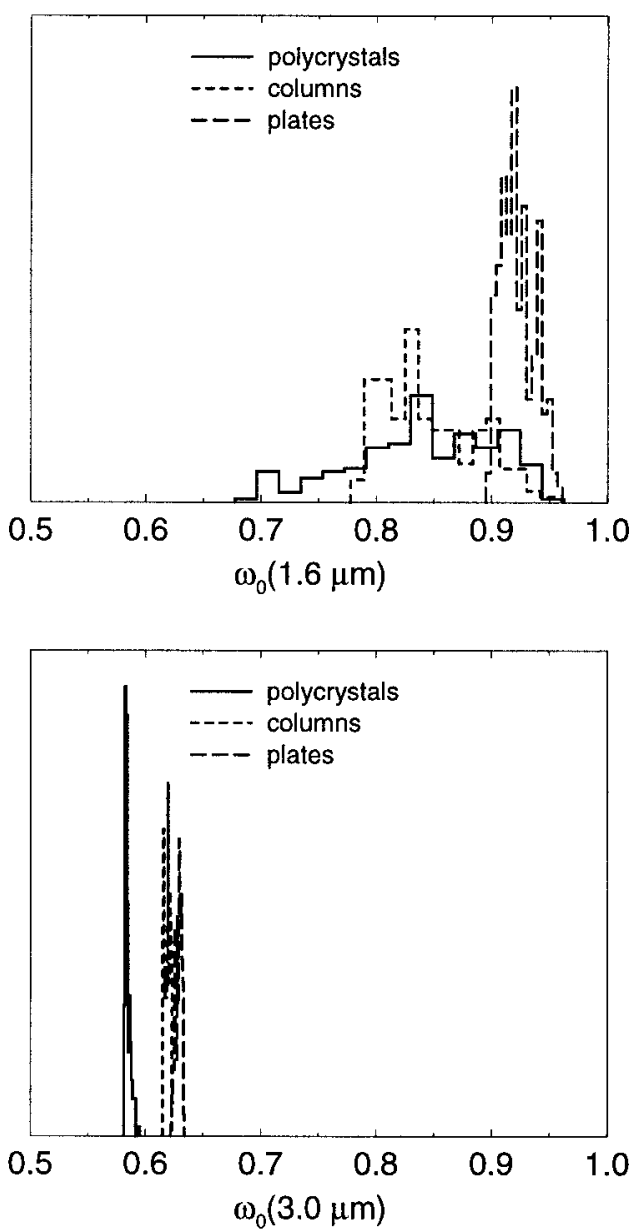

FIG. 6. Frequency distributions (arbitrary units) of single scattering albedo at 1.6 and $3.0 \mu \mathrm{m}$ for the midlatitude SDs.

sorption tends to attenuate the dependence of light scattering on the particle shape, the differences in $\langle g\rangle$ for columns, plates, and polycrystals are still about twice as large as the largest standard deviation in $\langle g\rangle$ (for the polycrystals) at this wavelength.

At the strong absorbing wavelength of $3.0 \mu \mathrm{m}$, the largest portion of the incident light is absorbed by the particles and the variations in asymmetry parameter and single scattering albedo due to different SDs reduces strongly. The small remaining size dependence of light scattering at this wavelength is not sufficient to over-

TABLE 7. Mean value and standard deviation (in parentheses) of asymmetry parameter and single scattering albedo for the midlatitude cirrus cases.

\begin{tabular}{lccc}
\hline \hline & Polycrystals & Columns & Plates \\
\hline$\langle g\rangle(0.5 \mu \mathrm{m})$ & $0.740(0.001)$ & $0.825(0.016)$ & $0.914(0.015)$ \\
$\langle g\rangle(1.6 \mu \mathrm{m})$ & $0.822(0.030)$ & $0.884(0.023)$ & $0.936(0.015)$ \\
$\langle g\rangle(3.0 \mu \mathrm{m})$ & $0.876(0.003)$ & $0.903(0.001)$ & $0.909(0.001)$ \\
$\left\langle w_{0}\right\rangle(1.6 \mu \mathrm{m})$ & $0.840(0.062)$ & $0.845(0.040)$ & $0.922(0.014)$ \\
$\left\langle w_{0}\right\rangle(3.0 \mu \mathrm{m})$ & $0.584(0.002)$ & $0.619(0.002)$ & $0.629(0.003)$ \\
\hline
\end{tabular}


come the differences due to the different particle shapes. Polycrystals always provide smaller $\langle g\rangle$ and smaller $\left\langle\omega_{0}\right\rangle$ values than the hexagonal particles. The differences are about 10 times larger than the scatter for the individual distributions. Differences in $\langle g\rangle$ for columns and plates are still twice as large as the standard deviation of their distributions.

\section{Summary and conclusions}

Our analysis of ice particle SDs shows that the volume extinction coefficient and thus the optical thickness of cirrus clouds is more determined by the crystal concentration than by particle sizes (see Fig. 4). Furthermore, it turns out that the mean single scattering properties (i.e., asymmetry parameter and single scattering albedo) are more sensitive to crystal shape than to particle size distributions (see Fig. 5). This is most pronounced at the nonabsorbing visible wavelengths, that is, at the maximum of the incoming solar irradiation. This leads to the conclusion that the broadband solar radiative properties of cirrus clouds are determined primarily by number density and particle shape rather than by the particle size.

Our findings that effective particle size (and thus mean scattering properties) and total number density (and thus optical thickness) are essentially uncorrelated suggests using both as independent microphysical parameters. This situation might simplify the modeling of three-dimensional cloud radiative transfer, since spatial variations in optical thickness do not have to be accompanied by corresponding variations in the mean single scattering properties.

While the present study only considered SDs consisting of one ice particle type, that is, either columns, plates, or polycrystals, real SDs may contain a mixture of crystal shapes, which strongly affects the mean scattering properties at both absorbing and nonabsorbing wavelengths. A typical example is the change in particle habit with size as reported in numerous in situ measurements (e.g., Heymsfield and McFarquhar 1996). Although a large number of in situ measurements of cirrus clouds microphysical properties exist, such size-shape correlations have not been sufficiently explored yet. Optical array probe measurements as used in the present paper are difficult to interpret in terms of actual particle shapes, because the measured projected area is not uniquely related to the shape of the crystals. Some recent papers address this problem (e.g., Duroure et al. 1994; Iaquinta et al. 1995). Applying the results of such studies to the SDs presented here will be a promising continuation of our work. Other interesting sources of data are holographic measurements obtained during the ICE (Krupp 1992) and from the Subsonic Contrails and Clouds Effects Special Study as well as spatially high resolved video images from the Video Ice Particle Sampler (Heymsfield and McFarquhar 1996). These kind of data will also help to define the role of small ice particles
$(<20-100 \mu \mathrm{m})$ that are not adequately detected by the optical array probe measurements.

Acknowledgments. We thank D. L. Mitchell and two anonymous reviewers for valuable comments and suggestions. The work of A. Macke was partly supported by the NASA FIRE III program. The work of G. M. McFarquhar is supported by the NSF Climate Dynamics Program, NSF Award ATM-9640613.

\section{REFERENCES}

Auer, A. H., and D. L. Veal, 1970: The dimensions of ice crystals in natural clouds. J. Atmos. Sci., 27, 919-926.

Baumgardner, D., and A. Korolev, 1997: Airspeed corrections for optical array probe sample volumes. J. Atmos. Oceanic Technol., 14, 1224-1229.

Chepfer, H., G. Brogniez, and Y. Fouquart, 1997: Determination of a radiatively equivalent microphysics for cirrus clouds by POLDER measurements-Sensitivity of radiative fluxes to the microphysics. IRS'96: Current Problems in Atmospheric Radiation, W. L. Smith and K. Stamnes, Eds., A. Deepak, 86-89.

Descloitres, J., J. C. Buriez, F. Parol, and Y. Fouquart, 1997: Comparison between cloud bidirectional reflectances observed by Polder and simulations based on the cloud microphysics used in the isccp scheme. IRS'96: Current Problems in Atmospheric Radiation, W. L. Smith and K. Stamnes, Eds., A. Deepak, 105108.

Duroure, C., H. Larsen, P. Personne, and H. Isaka, 1994: 2D image population analysis. Atmos. Res., 34, 195-205.

Francis, P. N., 1995: Some aircraft observations of the scattering properties of ice crystals. J. Atmos. Sci., 52, 1142-1154.

Gardiner, A. B., and J. Hallet, 1985: Degradation of in-cloud forward scattering spectrometer probe measurements in the presence of ice particles. J. Atmos. Oceanic Technol., 2, 171-180.

Gayet, J.-F., P. R. A. Brown, and F. Albers, 1993: A comparison of in-cloud measurements obtained with six PMS 2D-C probes. $J$. Atmos. Oceanic Technol., 10, 180-194.

— O. O. Crepel, and J.-F. Fournol, 1995: A new polar nephelometer for in situ measurements of microphysical and optical properties of clouds. Proc. Conf. on Cloud Physics, Dallas, TX, Amer. Meteor. Soc., 26-30.

- , G. Febvre, G. Brogniez, H. Chepfer, W. Renger, and P. Wendling, 1996: Microphysical and optical properties of cirrus and contrails: Cloud field study on 13 October 1989. J. Atmos. Sci., 53, 126-138.

Heymsfield, A. J., and L. M. Miloshevich, 1995: Relative humidity and temperature influences on cirrus formation and evolution: Observations from wave clouds and FIRE II. J. Atmos. Sci., 52, 4302-4326.

— tropical Pacific warm pool: Microphysical interpretations from CEPEX and from Kwajalein, Marshall Islands. J. Atmos. Sci., 53, 2424-2451.

Hignett, P., P. N. Francis, and A. Macke, 1997: Aircraft multispectral radiance measurements of cirrus during EUCREX'93, and their application to the retrieval of the clouds microphysical and radiative properties. IRS'96: Current Problems in Atmospheric Radiation, W. L. Smith and K. Stamnes, Eds., A. Deepak, 101104.

Hobbs, R., B. Morrison, R. Ashenden, and R. F. Ide, 1996: Comparison of two data processing techniques for optical array probes. Proc. FAA Int. Conf. on Aircraft Inflight Icing, Springfield, VA, Federal Aviation Administration, 69-90.

Iaquinta, J., H. Isaka, and P. Personne, 1995: Scattering phase function of bullet rosette ice crystals. J. Atmos. Sci., 52, 1401-1413.

Kinne, S., and K. N. Liou, 1989: The effects of the nonsphericity 
and size distribution of ice crystals on the radiative properties of cirrus clouds. Atmos. Res., 24, 273-284.

— T. A. Ackermann, A. J. Heymsfield, F. P. J. Valero, K. Sassen, and J. Spinhirne, 1992: Cirrus microphysics and radiative transfer: Cloud field study on 28 October 1991. Mon. Wea. Rev., 120, 661-684.

— , and Coauthors, 1997: Cirrus cloud radiative and microphysical properties from ground observations and in-situ measurements during FIRE'91 and their applications to exhibit problems in cirrus solar radiative transfer modeling. J. Atmos. Sci., 54, 2320 2344

Krupp, C., 1992: Holographische Messungen an Eiskristallen in Cirruswolken waehrend des Internationalen Cirrus Experiments ICE. External Rep. GKSS 92/E/14, GKSS Research Center, Geesthacht, Germany, 145 pp.

Macke, A., 1993: Scattering of light by polyhedral ice crystal. Appl. Opt., 32, 2780-2788.

— , and M. I. Mishchenko, 1996: Applicability of regular particle shapes in light scattering calculations for atmospheric ice particles. Appl. Opt., 35, 4291-4296.

—, M. I. Michshenko, K. Miunonen, and B. E. Carlson, 1995: Scattering of light by large nonspherical particles: Ray tracing approximation versus T-matrix method. Opt. Lett., 20, 1934 1936

_, J. Mueller, and E. Raschke, 1996: Single scattering properties of atmospheric ice crystals. J. Atmos. Sci., 53, 2813-2825.

_, M. I. Mishchenko, B. E. Carlson, and K. Muinonen, 1997: Scattering of light by large spherical, spheroidal, and circular cylindrical scatterers: Geometrical optics approximation versus T-matrix method. IRS'96: Current Problems in Atmospheric Radiation, W. L. Smith and K. Stamnes, Eds., A. Deepak, 822825.

McFarquhar, G. M., and A. J. Heymsfield, 1996: Microphysical characteristics of three anvils sampled during the Central Equatorial Pacific Experiment (CEPEX). J. Atmos. Sci., 53, 2401-2423.

, and — 1997: Parameterization of tropical cirrus ice crystal size distribution and implications for radiative transfer: Results from CEPEX. J. Atmos. Sci., 54, 2187-2200.

— , and - 1998: The definition and significance of an effective radius for ice clouds, J. Atmos. Sci, 55, 2039-2052.

Mitchell, D. L., and W. P. Arnott, 1994: A model predicting the evolution of ice particle size spectra and radiative properties of cirrus clouds. Part II: Dependence of absorption and extinction on ice crystal morphology. J. Atmos. Sci., 51, 817-832.

— A. Macke, and Y. Liu, 1996: Modeling cirrus clouds. Part II: Treatment of radiative properties. J. Atmos. Sci., 53, 2967-2988.

Posse, P., and W. von Hoyningen-Huene, 1996: Information about scattering properties and particle characteristics of a stratiform cloud at Helgoland by remote optical measurements. Contrib. Atmos. Phys., 68, 359-366.

Raschke, E., J. Schmetz, J. Heintzenberg, R. Kandel, and R. Saunders, 1990: The international cirrus experiment (ICE) - A joint European effort. Europ. Space Agency J., 14, 193-199.

— and Coauthors, 1996: European Cloud and Radiation Experiment (EUCREX). Final Rep. on the project EV5V-CT-0130 EUCREX-2, 154 pp. [Available from GKSS Research Center, Postfach 1160, D-21494 Geesthacht, Germany.]

Spinhirne, J. D., W. D. Hart, and D. Havlaka, 1996: Cirrus infrared parameters and shortwave reflectance relations from observations. J. Atmos. Sci, 53, 1438-1458.

Stackhouse, P. W. J., and G. L. Stephens, 1991: A theoretical and observational study of the radiative properties of cirrus: Results from FIRE 1986. J. Atmos. Sci., 48, 2044-2059.

Starr, D. O., 1987: Cirrus-cloud experiment: Intensive field observations planned for FIRE. Bull. Amer. Meteor. Soc., 68, 119124.

Takano, Y., and K. Jayaweera, 1985: Scattering phase matrix for hexagonal ice crystals computed from ray optics. Appl. Opt., 24, $3254-3263$.

- and K. N. Liou, 1989: Solar radiative transfer in cirrus clouds. Part I: Single-scattering and optical properties of hexagonal ice crystals. J. Atmos. Sci., 46, 3-18.

$\longrightarrow$, and -1995 : Radiative transfer in cirrus clouds. Part III: Light scattering by irregular ice crystals. J. Atmos. Sci., 52, 818 837

Warren, S. G., 1984: Optical constants of ice from the ultraviolet to the microwave. Appl. Opt., 23, 1206-1225.

Wielaard, D. J., M. I. Mishchenko, A. Macke, and B. E. Carlson, 1997: Improved T-matrix computations for large, nonabsorbing and weakly absorbing nonspherical particles and comparison with geometric optics approximation. Appl. Opt., 36, 43054313.

Yang, P., and K. N. Liou, 1995: Light scattering by hexagonal ice crystals: Comparison of finite difference time domain and geometric optic models. J. Opt. Soc. Amer. A, 12, 162-176. 